\title{
Tracheal pleomorphic adenoma with coexisting pulmonary tuberculoma
}

\author{
Jehun Kim, Chul-Ho Oak, Tae-Won Jang, Mann-Hong Jung \\ Department of Pulmonary and Critical Care Medicine, Kosin University Gospel Hospital, \\ Kosin University College of Medicine, Busan, Korea
}

\begin{abstract}
Tracheal tumors are rare and difficult to diagnose. Moreover, delays in diagnosis are very common because the symptoms are nonspecific. As a result, tracheal tumors are commonly mistreated as chronic obstructive pulmonary disease or bronchial asthma. We report a case of a 49-year-old male who presented with a 3month history of dyspnea and cough. Chest computed tomography scan showed a $1.5 \times 1.3 \mathrm{~cm}$ homogenous tumor originating from the right lateral wall of the tracheobronchial angle into the tracheal lumen as well as a $0.5 \times 0.4 \mathrm{~cm}$ round nodular lesion at the right upper lobe with multiple mediastinal lymph nodes enlargement. Bronchoscopic findings revealed a broad-based, polypoid lesion nearly obstructing the airway of the right main bronchus. The patient was diagnosed with pleomorphic adenoma which is the most common benign tumor of the salivary glands, but rarely appears in the trachea. Upon surgery, tracheal pleomorphic adenoma and co-existing active pulmonary tuberculoma that had been mistreated as bronchial asthma over 3 months was revealed. Following surgery, the patient underwent anti-tuberculosis treatment. No recurrence has been detected in the 3 years since treatment and the patient is now asymptomatic.
\end{abstract}

Keywords: Tracheal neoplasms; Pleomorphic adenoma; Pulmonary tuberculosis

\section{INTRODUCTION}

Pleomorphic adenoma is a salivary-gland type neoplasm that is very rare in the trachea, although it is commonly seen in the parotid gland. Because of the lack of early specific symptoms, diagnosis is often delayed, and the condition is usually mistreated as chronic obstructive pulmonary disease or bronchial asthma. To our knowledge, there have been only a few cases of tracheal pleomorphic adenoma with coexisting pulmonary tuberculosis reported worldwide (Table 1) [1].

We report a case of pleomorphic adenoma of the trachea

Received: September 30, 2017, Revised: November 13, 2017 Accepted: November 14, 2017

Corresponding Author: Chul-Ho Oak, Department of Internal Medicine, Kosin University College of Medicine, 262, Gamcheon-ro, Seo-gu, Busan 49267, Korea Tel: +82-51-990-6104, Fax: +82-51-990-3049 E-mail: oaks70@hanmail.net with coexisting active pulmonary tuberculoma treated by surgical resection and anti-tuberculosis medications, which was initially mistreated as bronchial asthma.

\section{CASE}

A 49-year-old male patient was referred to our hospital due to a 3-month history of exacerbation of dyspnea on exertion, cough and sputum. He was a current smoker with a 20year history of smoking two packs of cigarettes per day and was receiving medication for bronchial asthma including bronchodilator inhalation therapy for the last 12 months. Despite the medication, his symptoms were becoming aggravated. On physical examination, he also had expiratory and inspiratory wheezing on the right chest, but there was no weight loss or lymphadenopathy on the neck area. Blood chemistry revealed no abnormalities except for elevations in neuron-specific enolase (18.09 ng/mL; range, 0-17.3 ng/mL). The pulmonary func-

Copyright (C) 2018 Yeungnam University College of Medicine

This is an Open Access article distributed under the terms of the Creative Commons Attribution Non-Commercial License (http://creativecommons.org/licenses/by-nc/4.0/) which permits unrestricted non-commercial use, distribution, and reproduction in any medium, provided the original work is properly cited. 
Table 1. Comparison of seven cases of tracheal pleomorphic adenoma

\begin{tabular}{|c|c|c|c|c|c|c|c|c|}
\hline Case & Age & Sex Tumor site & Type of treatment & Size $(\mathrm{cm})$ & Imuunohistochemical stain & Comorbidity & Complication & Reference \\
\hline 1 & 59 & $\begin{array}{l}\text { M Left lateral } \\
\text { inner wall of } \\
\text { the trachea }\end{array}$ & $\begin{array}{l}\text { Right thoracotomy with } \\
\text { segmental resection and } \\
\text { end-to-end anastomsis }\end{array}$ & $2.0 \times 2.0$ & $\begin{array}{l}+: \text { CK, CK-19, EMA, } \\
\text { S100, p63 }\end{array}$ & $(-)$ & $(-)$ & [1] \\
\hline 2 & 71 & $\begin{array}{l}\text { M Left main } \\
\text { bronchus }\end{array}$ & Electrosurgical snaring & $2.5 \times 2.0$ & $+:$ CK AE1/AE3, $\alpha-\mathrm{SMA}$ & $\begin{array}{l}\text { Squamous cell } \\
\text { carcinoma }\end{array}$ & $(-)$ & [14] \\
\hline 3 & 71 & $\begin{array}{l}\text { M Left main } \\
\text { bronchus }\end{array}$ & Electrosurgical snaring & $\begin{array}{l}\text { Not } \\
\text { described }\end{array}$ & +: S100, anti-GFAP & $(-)$ & $(-)$ & [9] \\
\hline 4 & 65 & $\begin{array}{c}\text { M Right main } \\
\text { bronchus }\end{array}$ & Electrosurgical snaring & 1.3 & Not described & $(-)$ & $(-)$ & [11] \\
\hline 5 & 37 & $\begin{array}{l}\text { M Posterior wall } \\
\text { of the trachea }\end{array}$ & $\begin{array}{l}\text { Excised with cold } \\
\text { instruments }\end{array}$ & $2.0 \times 2.0$ & Not described & $(-)$ & $(-)$ & [2] \\
\hline 6 & 42 & $\begin{array}{l}\text { F Distal part of } \\
\text { trachea }\end{array}$ & $\begin{array}{l}\text { Right thoracotomy with } \\
\text { segmentall resection and } \\
\text { end-to-end anastomsis }\end{array}$ & $2.0 \times 2.0$ & +: Vimentin, GFAP, S100 & $(-)$ & $\begin{array}{l}\text { Stenosis in } \\
\text { anastomosis } \\
\text { site }\end{array}$ & [12] \\
\hline 7 & 49 & $\begin{array}{l}\text { M Right lateral } \\
\text { inner wall of } \\
\text { the trachea }\end{array}$ & $\begin{array}{l}\text { Right thoracotomy with } \\
\text { segmental resection and } \\
\text { end-to-end anastomsis }\end{array}$ & $1.5 \times 1.3$ & +: CK, CK 5/6, p53 & $\begin{array}{l}\text { Pulmonary } \\
\text { tuberculoma }\end{array}$ & $(-)$ & Our case \\
\hline
\end{tabular}

CK, cytokeratin; EMA, epithelial membrane antigen; $\alpha$-SMA, alpha-smooth muscle actin, GFAP, glial fibrilliary acidic protein.

tion test revealed a severe obstructive defect (forced expiratory volume in 1 second $\left[\mathrm{FEV}_{1}\right], 1.59 \mathrm{~L}, 47 \%$ of predicted; forced vital capacity [FVC], $3.67 \mathrm{~L}, 80 \%$ of predicted; $\mathrm{FEV}_{1} /$ FVC, $43 \%$ of predicted, and no bronchodilator response). Chest $\mathrm{x}$-ray films showed a low-radiolucent round shadow in the lower trachea. Chest computed tomography (CT) revealed a $1.5 \times 1.3 \mathrm{~cm}$ homogenous tumor originating from the right lateral wall of the tracheobronchial angle into the tracheal lumen, as well as a $0.5 \times 0.4 \mathrm{~cm}$ round nodular lesion in the posterior zone of the right upper lobe (Fig. 1) with multiple mediastinal lymph nodes enlargement (subcarinal, right hilar [10R], right interlobar [11R]). Bronchoscopy identified a broad-based, polypoid lesion nearly obstructing the airway of the right main bronchus arising from the right lateral wall of the trachea at $0.5 \mathrm{~cm}$ above the carina. The rich blood vessels on the tumor surface were engorged (Fig. 2). The possible differential diagnoses were benign and malignant lesions, including carcinoids and tracheal carcinoma with lung and lymph nodes metastasis. There was no evidence of distant metastasis. Flexible bronchoscopic biopsy using forceps was inconclusive. Therefore, we employed a surgical approach to treatment of the lesion rather than a bronchoscopic procedure owing to the potential for airway obstruction and bleeding during the procedure because of the tumor size and rich vascularity of the tumor surface.

The patient underwent right thoracotomy with segmental resection and anastomosis with tracheobronchoplasty. Three tracheal rings were excised along with the tumor, after which lymph nodes dissection (subcarinal, 10R, 11R) and wedge resection of the right upper lobe nodule were conducted. On macroscopic examination, the excised mass appeared as a single, well-defined, round, firm polypoid mass measuring $1.5 \times$ $1.3 \times 1.3 \mathrm{~cm}$. The outer surface of the mass was surrounded by a thin capsule. As shown in Figure 3, the cut surface of the tracheal mass was homogenously solid and yellowish white without hemorrhage or necrosis.

On microscopic examination, the mass was composed of bronchial epithelial and myoepithelial cells in the chondromyxoid stroma. There were no definitive cellular pleomorphisms or mitotic figures, and the surgical margins of the resected trachea were free of tumor. Immunohistochemically, the epithelial cells were positive for cytokeratin 5/6. Moreover, the myoepithelial cells were immunoreactive for cytokeratin and p53, suggesting pleomorphic adenoma. In the wedge resection of the peripheral nodule in the right upper lobe, a well-defined $0.5 \times 0.4 \times 0.4 \mathrm{~cm}$ ovoid firm nodule was present. The cut surface of the nodule was homogenously solid and white with yellow spots. The nodule was diagnosed as active tuberculoma based on an acid-fast bacilli stain (Fig. 4) and positive tissue culture for Mycobacterium tuberculosis.

Because it was revealed as an active pulmonary tuberculoma, the patient also received 12-months of anti-tuberculosis 

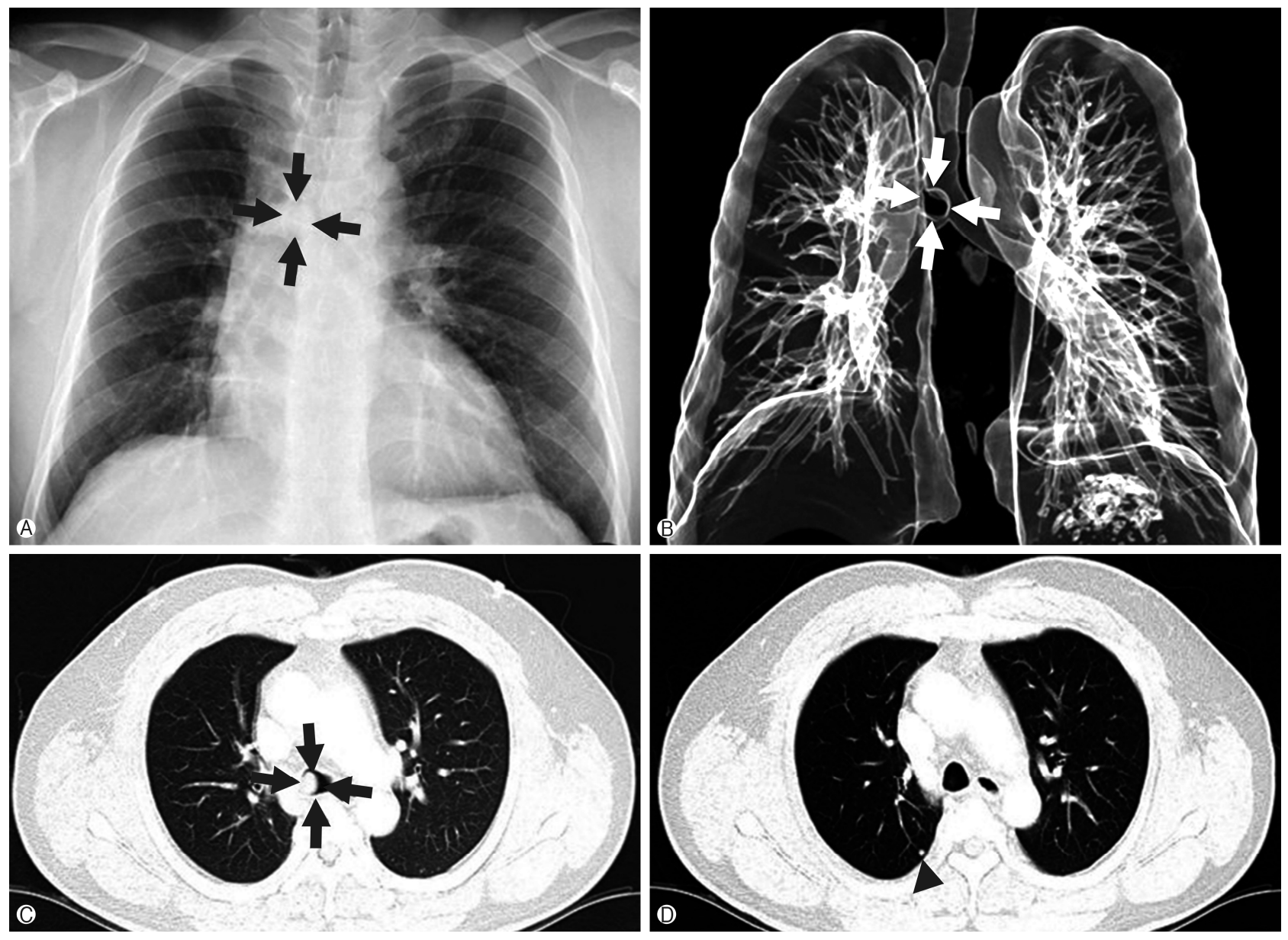

Fig. 1. (A) Chest x-ray shows a round mass shadow in the lower tracheal level (black arrows). (B) Three-dimensional airway CT shows a round mass in lower trachea level (white arrows). (C) Lung setting of CT scan of the chest shows a $1.5 \times 1.3 \mathrm{~cm}$ homogenous mass in the right lateral inner wall of the trachea (black arrows). (D) A $0.5 \times 0.4 \mathrm{~cm}$ round shaped nodule in the posterior zone of right upper lobe seen on the CT (arrowhead). CT, computed tomography.
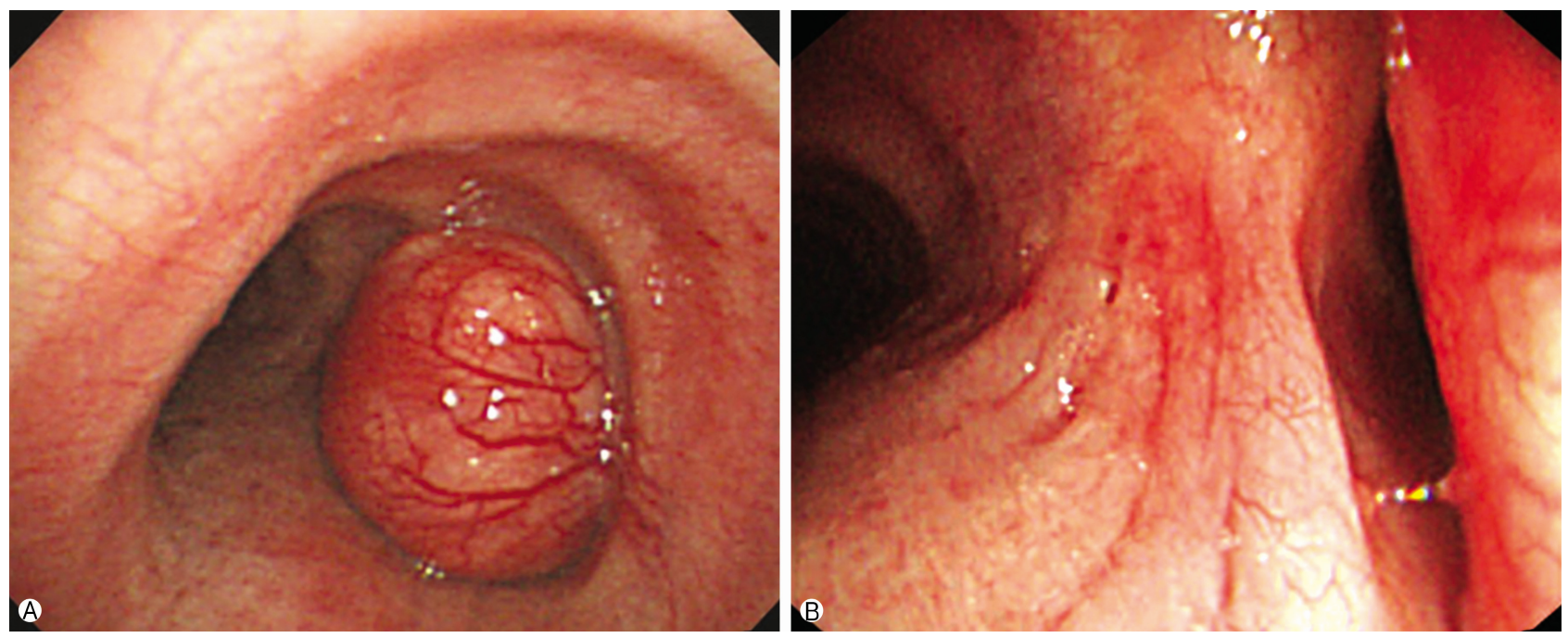

Fig. 2. (A) Bronchoscopic shows a polypoid and broad mass originated from right side of lower trachea have rich engorged blood vessels on the tumor surface. (B) The mass nearly occludes the orifice of right main bronchus. 
chemotherapy. There was no evidence of malignancy in the excised specimens. Dissected lymph nodes (subcarinal, 10R, 11R) were also reactive hyperplasia. Overall, these findings suggested a rare case of pleomorphic adenoma in the trachea combined with active pulmonary tuberculoma in the lung that was mistreated as bronchial asthma. The postoperative course was uneventful, and the patient has remained in good health for 3 years since the surgery. Postoperative bronchoscopy and chest CT showed no regrowth of the pleomorphic adenoma (Fig. 5).

\section{DISCUSSION}

Primary tumors of the trachea are rare, accounting for only $2 \%$ of upper airway tumors. Overall, their incidence is 0.1 per 100,000 [2]. In adults, approximately $90 \%$ of the primary tracheal tumors are malignant, whereas in children, the majority of these tumors are benign. Primary tracheal tumors can arise from the respiratory epithelium, salivary glands, and mesenchymal structure of the trachea [3].

Pleomorphic adenoma, which is also known as mixed tumor, is the most common tumor of the major salivary glands; however, these tumors rarely occur in the lung and they typically arise from the tracheal and bronchial seromucous glands [4,5]. Pleomorphic adenoma consist of benign neoplasms with mixed epithelial and mesenchymal components that usually develop on the posterolateral surface of the trachea or bronchus, where the glandular elements are most densely concentrated. The surface of these tumors generally shows a promi-

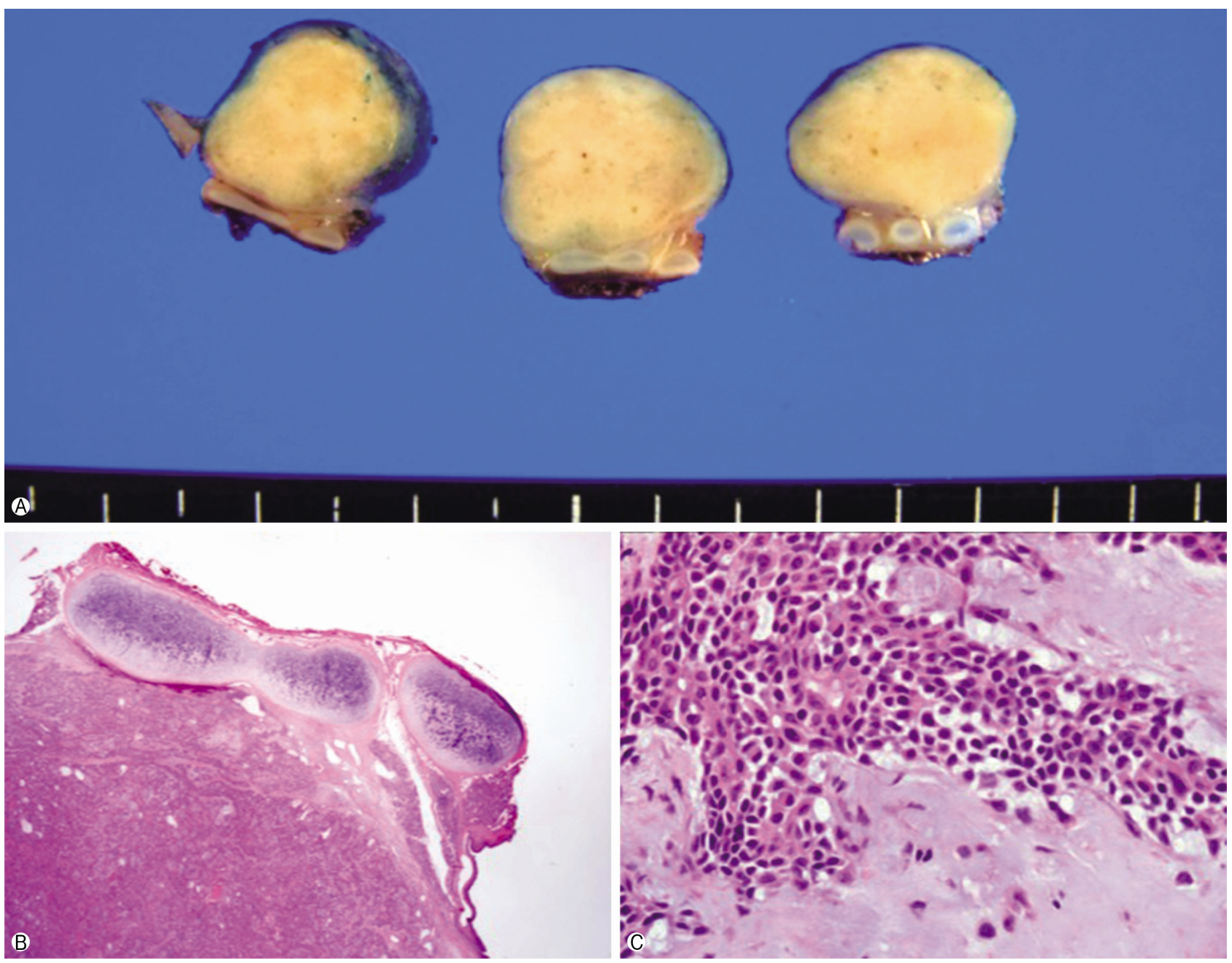

Fig. 3. The excised tumor. (A) Macroscopic appearance of the pleomorphic adenoma; there is a well-circumscribed grey colored measuring $1.5 \times 1.3 \times 1.3 \mathrm{~cm}$ mass; cut surface shows a well-defined ovoid mass without necrosis or invasion into the paratracheal tissues. (B, C) Microscopic appearance of the pleomorphic adenoma; ductal and myxoid components in the chondromyxoid stroma consisted of eosinophilic cuboidal epithelium and myoepithelium (H\&E stain, B, $\times 12.5$; $\mathrm{C}, \times 400)$. 
Jehun Kim et al.

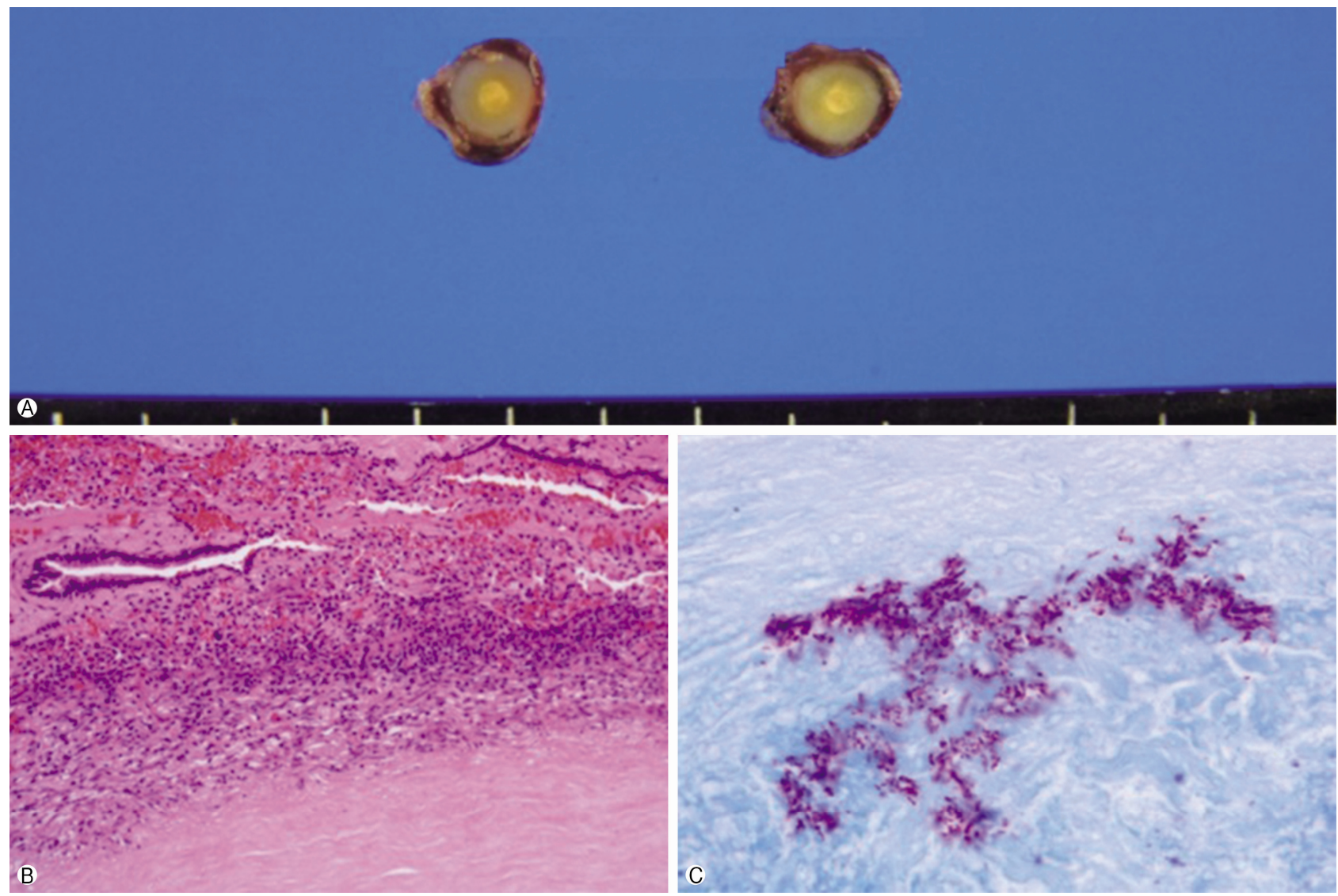

Fig. 4. Wedge resected nodule in the right upper lobe. (A) Macroscopic appearance of the lesion; surrounded by grey capsule, $0.5 \times 0.4 \times$ $0.4 \mathrm{~cm}$ ovoid nodule, the cut surface of the nodule is homogenously solid and white with yellow spot. (B) Chronic granulomatous inflammation with caseous necrosis $(\mathrm{H} \& \mathrm{E}$ stain, $\times 200)$. (C) Acid-fast stain-positive bacilli are identified $(\times 1,000)$.
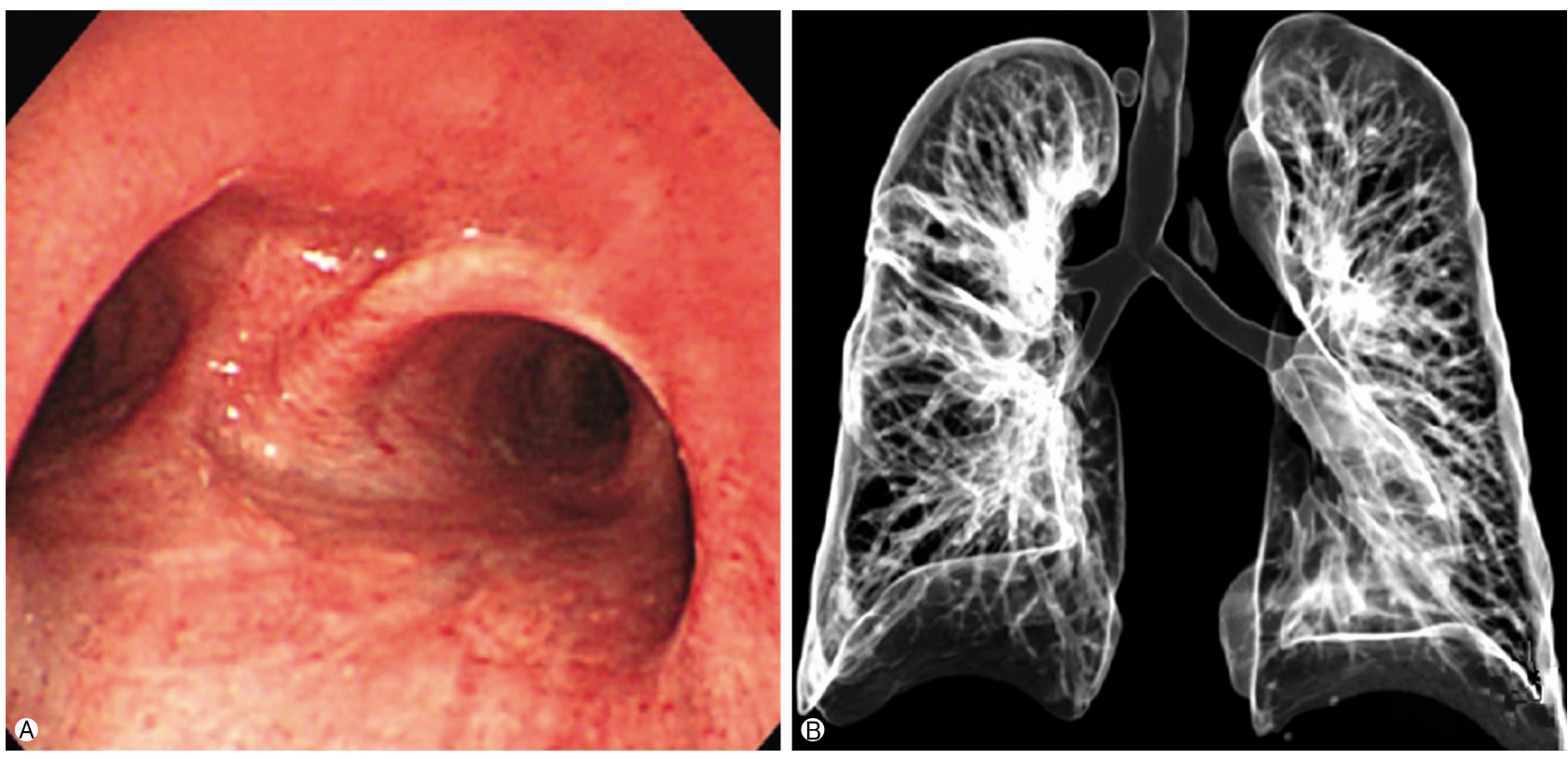

Fig. 5. The post-operative bronchoscopy and 3D airway CT at 2 years after operation (A, B) shows no recurrence of the tracheal lesion compared to pre-operative bronchoscopy and 3D airway CT. 3D, three-dimensional; CT, computed tomography. 
nent vascular pattern, as in this case, and microscopy shows epithelial and myoepithelial cells in a myxoid or chondroid matrix [6-9].

Because of their rarity and unpredictable oncologic behavior, there is no clear consensus regarding management and prognosis of pleomorphic adenoma [10,11].

We report a rare case of tracheal pleomorphic adenoma with coexisting active pulmonary tuberculoma. This condition is extremely rare. Indeed, to our knowledge there is only one other case report of pulmonary pleomorphic adenoma with a cavitary form of pulmonary tuberculosis in the literature, and no definitive incidence has been recorded [1].

Based on the few case reports in the literature, most occurrences of pleomorphic adenoma are found incidentally. The majority of patients present with symptoms such as cough, sputum production, dyspnea, wheeze, and stridor. Because of the slow tumor growth, these respiratory signs and symptoms are usually mistreated as asthma [12]; thus, proper diagnosis may be delayed.

Pleomorphic adenoma may not be discovered on plain chest posterior-anterior view; therefore, chest CT and bronchoscopy play crucial roles in diagnosis of the patient at presentation [13]. Our patient was also treated for asthma during the 12 months before a definitive diagnosis was made. As a result, these procedures should be performed for patients with asthma symptoms intractable to treatment.

In this case, our first impression was tracheal cancer with distant metastasis to the right upper lobe and mediastinal lymph nodes. However, surgery confirmed the diagnosis of benign tracheal pleomorphic adenoma with coexisting active tuberculoma of lung. There was no abnormality in the salivary glands; thus, it could be treated by curative surgery and subsequent anti-tuberculosis medications for 1 year.

The treatment of choice for tracheal pleomorphic adenoma is complete surgical excision [2]. A few case reports have reported that this condition could not only be treated by segmental resection of the trachea and end-to-end anastomosis, but also bronchoscopic removal with cold instruments, laser excision, cryotherapy, radiation, and an electrosurgical snare that can be applied for palliation when rapid recanalization or hemostasis is required $[2,11,13,14]$.

The biological behavior and clinical course of pleomorphic adenoma have not been well described because of the limited number of case reports; however, there have been reports of this tumor showing malignant and aggressive behavior [15]. Nevertheless, in the absence of histological features of malignancy such as necrosis and a high mitotic rate, pleomorphic adenoma is unlikely to show malignant features [6].

The patient showed marked improvement of respiratory distress after surgical treatment, which he had thought was because of bronchial asthma. There was no recurrence during 3 -years of follow-up based on periodic bronchoscopy and chest CT.

There is substantial prevalence of pulmonary tuberculosis by incidental finding. Moreover, this condition sometimes mimics malignant lesions before definite diagnosis. Accordingly, it is important to distinguish between benign and malignant disease because of the increase in the aging population and immunocompromised patients [16]. Although the incidence of tuberculosis is decreasing worldwide, a high index of suspicion must be maintained for the diagnosis of pulmonary masses to prevent overestimation of disease and provide optimal treatment.

In conclusion, tracheal pleomorphic adenoma, particularly as a primary lesion, is a very rare occurrence. Moreover, this condition can mimic asthma; therefore, tracheal tumors may be considered in the differential diagnosis of patients with intractable asthma-like symptoms. Additionally, it should be kept in mind that this rare entity may mimic intractable asthma to prevent delays in diagnosis. CT and bronchoscopy may prove valuable in patients with asthma-like symptoms, especially if the response to treatment is unsatisfactory.

\section{CONFLICT OF INTEREST}

No potential conflict of interest relevant to this article was reported.

\section{ORCID}

Jehun Kim, https://orcid.org/0000-0002-2594-0256

Chul-Ho Oak, https://orcid.org/0000-0002-8254-5607

\section{REFERENCES}

1. Park KS, Sung WJ. Pleomorphic adenoma of the trachea: a case report. Korean J Pathol 2013;47:399-401.

2. Ashwaq AM, Sani A. Pleomorphic adenoma of the trachea. 
Med J Malaysia 2007;62:162-3.

3. Chowdhury Q, Rahman MA, Sultana L, Islam MA, Chowdhury GM. Tracheal adenocarcinoma treated with adjuvant radiation: a case report and literature review. Case Rep Oncol 2013;6:280-4.

4. Pinkston JA, Cole P. Incidence rates of salivary gland tumors: results from a population-based study. Otolaryngol Head Neck Surg 1999;120:834-40.

5. Spencer H. Bronchial mucous gland tumours. Virchows Arch A Pathol Anat Histol 1979;383:101-15.

6. Moran CA, Suster S, Askin FB, Koss MN. Benign and malignant salivary gland-type mixed tumors of the lung. Clinicopathologic and immunohistochemical study of eight cases. Cancer 1994;73:2481-90.

7. Ang KL, Dhannapuneni VR, Morgan WE, Soomro IN. Primary pulmonary pleomorphic adenoma. An immunohistochemical study and review of the literature. Arch Pathol Lab Med 2003;127:621-2.

8. Payne WS, Schier J, Woolner LB. Mixed tumors of the bronchus (salivary gland type). J Thorac Cardiovasc Surg 1965;49: 663-8.

9. Matsubara M, Yasuo M, Tanabe T, Tsushima K, Urushihata $\mathrm{K}$, Yamamoto $\mathrm{H}$, et al. Pleomorphic adenoma with an endo- bronchial resection. Intern Med 2008;47:1117-20.

10. Tanigaki T, Shoyama Y, Iwasaki M, Abe Y, Nakamura M, Inoue H. Pleomorphic adenoma in the lung. Monaldi Arch Chest Dis 2002;57:30-2.

11. Fitchett J, Luckraz H, Gibbs A, O'Keefe P. A rare case of primary pleomorphic adenoma in main bronchus. Ann Thorac Surg 2008;86:1025-6.

12. Aribas OK, Kanat F, Avunduk MC. Pleomorphic adenoma of the trachea mimicking bronchial asthma: report of a case. Surg Today 2007;37:493-5.

13. Schneider P, Schirren J, Muley T, Vogt-Moykopf I. Primary tracheal tumors: experience with 14 resected patients. Eur J Cardiothorac Surg 2001;20:12-8.

14. Goto T, Maeshima A, Akanabe K, Hamaguchi R, Wakaki M, Oyamada Y, et al. Bronchial pleomorphic adenoma coexisting with lung cancer. Ann Thorac Cardiovasc Surg 2011;17:174-7.

15. Demirağ F, Topçu S, Kurul C, Memiş L, Altinok T. Malignant pleomorphic adenoma (malignant mixed tumor) of the trachea: a case report and review of the literature. Eur Arch Otorhinolaryngol 2003;260:96-9.

16. Shim TS. Diagnosis and treatment of latent tuberculosis infection. Korean J Med 2012;82:284-90. Korean. 